\title{
A proteção ressarcitória do Estado e o princípio da proteção da confiança*
}

\section{Protection of compensation of State and the principle of the protection of trust}

\author{
Rafael Da Cás Maffini** \\ Josiane Rigon***
}

RESUMO

O presente trabalho analisa a responsabilidade civil do Estado nos casos de alteração das normas indutivas e do não cumprimento das promessas estatais. Para a compreensão desses elementos, aborda-se a frustração da expectativa do indivíduo quando depositada a confiança em determinada

* Artigo recebido em 8 de maio de 2013 e aprovado em 4 de setembro de 2013.

** Professor de direito administrativo; mestre e doutor em direito pela UFRGS; advogado em Porto Alegre; sócio diretor do escritório Rossi, Maffini \& Milman Advogados. Rossi, Maffini \& Milman Advogados, Porto Alegre, Brasil. E-mail: rafael@rmm.com.br.

*** Mestranda do Programa de Pós-Graduação Stricto Sensu em Direito da Universidade de Santa Cruz do Sul. Possui pós-graduação em direito do estado pela Universidade Federal do Rio Grande do Sul (UFRGS). Graduada em direito pela Pontifícia Universidade Católica do Rio Grande do Sul (PUC-RS). Integrante do Grupo de Pesquisas "Políticas Públicas no tratamento dos conflitos" coordenado pela professora pós-doutora Fabiana Marion Spengler e viceliderado pelo professor Theobaldo Spengler Neto. Advogada e coordenadora acadêmica EAD na Universidade Anhanguera (Uniderp). Universidade Anhanguera, Porto Alegre, Brasil. E-mail: jo_rigon@hotmail.com. 
conduta estatal. Busca-se a compreensão do dever que o Estado tem de indenizar o particular com observância ao princípio da confiança.

\section{PALAVRAS-CHAVE}

Confiança - descumprimento - Estado - indução - normas promessa - responsabilidade

\section{ABSTRACT}

This paper analyzes the state liability in cases of amendment of the rules of inductive and non-fulfillment of promises state. To understand these elements we address the requirements of the Liability of the State and the frustration of the expectation of the individual when the trust deposited in a particular state conduct. The aim is to understand the duty that the state has to compensate the individual in compliance with the principle of trust.

\section{KEYWORDS}

Trust - breach - State - induction standards - promise - accountability

\section{Introdução}

Ao longo dos anos, a responsabilidade civil do Estado sofreu modificações em nosso ordenamento levadas pelas tendências atuais. O campo da responsabilidade civil extracontratual do Estado abrange os efeitos danosos, materiais ou morais, de ações e omissões imputáveis ao Estado ou a particulares prestadores de serviços públicos relativos a condutas de origem não contratual e que configurem infração a um dever jurídico.

Para tanto, será abordado o comportamento do Estado no seu âmbito, podendo este ensejar a expectativa legítima no particular. Esse é um princípio aplicável às relações jurídico-administrativas, extraído do sistema a partir do fato de que tenha gerado confiança - elemento essencial e aplicável quando a realidade forneça ao intérprete elementos adicionais - acidentais -, qualificando a conduta da outra parte como geradora de consequência juridicamente exigível. O princípio da confiança é pressuposto em todas as relações jurídicas, e tem na sua origem etimológica o vocábulo cum fides, que ocorre quando o cidadão tem fé (bona fide) na realização de determinado comportamento administrativo. 
Por conseguinte, necessário se faz o estudo do tema da responsabilidade civil do Estado nos casos de alteração das normas indutivas e do não cumprimento das promessas estatais. Este se apresenta como um dos pontos desafiadores na essência do direito administrativo. Então, tem excepcional relevo, quer sob a ótica do administrado, quer da administração pública. Seu reconhecimento ao longo da história vem sofrendo alterações, tendo como grande marco a Constituição de 1946, que introduziu a teoria da responsabilidade objetiva, e o Código Civil de 2002, demonstrando sintonia com toda evolução constitucional a qual abrangeu muito bem o tema.

Apresenta-se, aqui, um dos fundamentos do estado de direito mais ricos que é a responsabilidade civil, pois repara os danos que venha causar aos cidadãosadministrativos, do qual é consequência lógica e inevitável. Os princípios e postulados do estado de direito regem e obrigam ao próprio Estado, sem deixar de ter em foco a prevalência do interesse público. Um dos princípios de maior relevância na teoria geral de direito, mesmo não encontrado de forma explícita na Constituição da República Federativa do Brasil (CF), ou seja, no elenco dos princípios constitucionais da administração pública, é o princípio da proteção da confiança.

Averiguar-se-á sobre referido princípio, eis que contém, claramente, um elemento ético da maior relevância incorporado ao direito pela jurisprudência e que anteriormente era simplesmente moral e não jurídico. O Estado, em alguns casos, incentiva claramente os indivíduos a seguirem determinado comportamento, mediante promessas concretas de vantagens e benefícios. Tal fato enseja indenização por parte do Estado pelos danos decorrentes da confiança, infringindo também princípios importantíssimos, como da segurança jurídica e da boa-fé.

Não obstante o grande valor extraordinário do tema, a doutrina brasileira é carente em sua abordagem. As referências nas obras gerais são limitadas, ou seja, não adentram na questão. E as incursões monográficas são raríssimas. Portanto, propõe-se como objetivo principal do artigo o debate de soluções possíveis para os problemas que surgem a partir do exame da proteção ressarcitória do Estado nos casos de alteração das normas indutivas e do não cumprimento das promessas estatais.

\section{A conduta estatal: frustração da expectativa}

Discorrerá aqui sobre o tema da ação do Estado e as consequências que dela sobrevêm tendo em vista a expectativa depositada pelo indivíduo. 
Compreendendo quais aquelas atribuídas no órgão estatal que merecem proteção legítima. ${ }^{1}$

$\mathrm{O}$ Estado pode intervir na economia agindo como se fosse um agente econômico, em concorrência com os particulares. E, também, pode intervir sobre o domínio econômico, representando a ação legislativa em sentido amplo, a compreender leis e regulamentos, sobressaindo-se normas diretivas, a determinarem coercitivamente comportamentos, como imposição de tabela de preços, e normas indutivas, as quais, facultativamente, apenas inspiram os particulares a atuarem de maneira que interessa ao poder público; é o que ocorre na criação de estímulos ou incentivos propiciadores da prática de um determinado comportamento pelo administrado. ${ }^{2}$

Os órgãos ou autoridades públicas, ao se pronunciarem no mundo jurídico, provocando o nascimento de legítimas expectativas, as tutelam, podendo ocorrer até o dever de não invalidar ou revogar atos ilegais se já consolidadas pelo tempo certas situações, tendo-se, então, por sanada a invalidade originária. Deve-se tudo isso à confiança, que implicará a relativa restrição a certos poderes da administração pública. ${ }^{3}$ Quanto a esta, Mello ${ }^{4}$ ressalta que, ao não realizar o comportamento legitimamente esperado pelo particular, não leva o Judiciário a definir qual obrigação deverá adimplir, mas sim a extensão de sua responsabilidade pelo cumprimento da obrigação.

Um exemplo que relata perfeitamente a figura da expectativa legítima nos atos administrativos é a exposição de motivos das medidas provisórias tributárias, a qual é feita para convencer o Congresso. Diante do fato de o contribuinte ser representado pelo Parlamento, a concretização da expectativa legítima ocorrerá mediante ação judicial. ${ }^{5}$

Assim, podemos afirmar que a expectativa legítima é um princípio aplicável às relações jurídico-administrativas, visando estabelecer um estado de tutela jurídica - direta ou indireta, positiva ou negativa - das expectativas

1 MAFFINI, Rafael Da Cás. Princípio da proteção substancial da confiança no direito administrativo brasileiro. Porto Alegre: Verbo Jurídico, 2006. p. 46.

2 NOBRE JÚNIOR, Edílson Pereira. O princípio da boa-fé e sua aplicação no direito administrativo brasileiro. Porto Alegre: Sérgio Antônio Fabris, 2002. p. 290.

3 MARTINS-COSTA, Judith. A proteção da legítima confiança nas relações obrigacionais entre a administração e os particulares. Revista da Faculdade de Direito da Universidade Federal do Rio Grande do Sul, Porto Alegre, n. 22, p. 228-257, set. 2002. p. 237.

4 MELLO, Eduardo Brigidi de. O princípio da expectativa legítima e a exposição de motivos das medidas provisórias. Revista Tributária e de Finanças Públicas, São Paulo: Revista dos Tribunais, v. 14, n. 66, p. 173-198, jan./fev. 2006. p. 181.

5 Ibid., p. 173. 
legitimamente depositadas pelos administradores em relação a condutas, procedimentos, promessas, ou atos perpetrados pelo Estado em sua atividade administrativa. ${ }^{6}$ Evidencia-se através de dois elementos: o essencial que é a situação fática que gera a confiança e o acidental que se aplica quando a realidade forneça ao intérprete elementos adicionais, qualificando a conduta da outra parte como geradora de consequência juridicamente exigível.

A expectativa gera confiança no indivíduo, resultante da constituição de um direito que o mesmo criou em razão da presença de fatos que conduzem à formação de um direito subjetivo. Ao mesmo tempo que ainda não se tem o direito, existem fatos os quais justificam a presunção da realização futura do direito, ora pela possibilidade concreta de realização de um fato futuro e incerto cuja pendência existe, ora pela iminência da ocorrência dos últimos fatos de uma cadeia de outros já ocorridos. ${ }^{7}$ Pode-se dizer então que é "a expectativa legítima que gerará proteção, e não a confiança, em que pese ser aquela derivada desta". ${ }^{8}$

Seguindo os mesmos preceitos, Porto 9 compreende que "as legítimas expectativas surgem de uma situação de fato que são amparadas por alguma norma protetora da confiança em função de um período de tempo que permita a perpetuação do estado em que se encontra". A expectativa legítima deve ser protegida por duas razões: a primeira porque, se frustrada, a expectativa poderá causar dano considerável a um indivíduo que nela depositou confiança. Segundo porque as expectativas estão relacionadas com a autonomia e com o planejamento de vida de cada particular.

Assim, a proteção das expectativas gera, em longo prazo, confiança nas autoridades públicas, bem como na maneira como estes entes percebem legitimidade e eficácia. ${ }^{10}$ Os requisitos da tutela da confiança podem ser formulados mediante a análise das normas constitucionais aplicáveis ao caso, bem como jurisprudência do Supremo Tribunal Federal (STF). O primeiro requisito é a relação entre um dos poderes estatais (Executivo, Legislativo ou Judiciário)

6 Maffini, Princípio da proteção substancial da confiança no direito administrativo brasileiro, op. cit., p. 59.

7 BRANCO, Gerson Luiz Carlos. A proteção das expectativas legítimas derivadas das situações da confiança: elementos formadores do princípio da confiança e seus efeitos. Revista de Direito Privado, n. 12, v. 3, p. 169-225, out./dez. 2002. p. 177.

8 Mello, O princípio da expectativa legítima e a exposição de motivos das medidas provisórias, op. cit., p. 183.

9 PORTO, Éderson Garin. O princípio da proteção da confiança e a boa-fé objetiva no direito público. Revista da Ajuris, Porto Alegre, v. 33, n. 102, p. 127-142, 2006. p. 141.

10 SHONBERG, Soren J. Legitimate expectations in administrative law. Oxford: Oxford, 2000. p. 29. 
com um ou mais particulares; o segundo são os atos ou comportamentos estatais a despertar a confiança do particular; o terceiro é a aparência de legitimidade do ato; o quarto é o nexo de causalidade entre o poder público e a confiança estimulada; e o quinto, e último, é a ocorrência de prejuízo ao particular. $^{11}$

No entanto, o Estado intervindo sobre o domínio econômico poderá ensejar situações, as quais poderão acarretar danos a terceiros quando decorrer de maltrato à boa-fé. Nesse sentido, Nobre Júnior ${ }^{12}$ afirma que duas são as situações: a alteração de normas indutivas e o desrespeito às promessas estatais, não divulgadas pela via normativa; situações essas objeto do presente trabalho.

\section{A proteção ressarcitória do Estado e o princípio da proteção da confiança}

Após ser analisada a responsabilidade civil do Estado, bem como a frustração da expectativa legítima diante da conduta estatal, busca-se conceituar o princípio da proteção da confiança no contexto jurídico brasileiro. Nos ensinamentos de Couto e Silva, extrai-se que: "a proteção à confiança, para alguns autores, é uma ramificação de natureza subjetiva do princípio da segurança jurídica, das pessoas no pertinente aos atos, procedimentos e condutas do Estado, nos mais diferentes aspectos de sua atuação" ${ }^{13}$

Várias consequências são retiradas desse princípio na atuação do Estado: uma delas é a imposição de limitações ao Estado na sua liberdade de alterar sua conduta e de modificar atos que produziram vantagens para os destinatários, mesmo quando ilegais; outra é o ganho patrimonial gerado por essas alterações, em virtude da crença depositada pelos beneficiários, pelos administrados ou pela sociedade em geral de que aqueles atos eram realmente legítimos, acreditando que seriam mantidos ou executados. ${ }^{14}$

11 Porto, O princípio da proteção da confiança e a boa-fé objetiva no direito público, op. cit., p. 141-142.

12 Nobre Júnior, O princípio da boa-fé e sua aplicação no direito administrativo brasileiro, op. cit., p. 291-292.

13 COUTO E SILVA, Almiro do. O princípio da segurança jurídica (proteção à confiança) no Direito Público Brasileiro e o direito da administração pública de anular seus próprios atos administrativos: o prazo decadencial do art. 54 da Lei do processo administrativo da União (Lei n. 9.784/99). Revista Brasileira de Direito Público - RBDP, Belo Horizonte, v. 2, n. 6, jul./set. 2004. p. 10.

14 Ibid., p. 10-11. 
Quanto a esta questão, observa Canotilho: ${ }^{15}$

O homem necessita de segurança para conduzir, planificar e conformar autônoma e responsavelmente a sua vida. Por isso, desde cedo se consideram os princípios da segurança jurídica e da proteção à confiança como elementos constitutivos do Estado de direito - enquanto a proteção da confiança se prende mais com as componentes subjetivas da segurança, designadamente a calculabilidade e previsibilidade dos indivíduos em relação aos efeitos jurídicos dos atos.

A eficácia do princípio da confiança pode se manifestar de duas maneiras: negativamente e positivamente. Na primeira, obrigações de não fazer, assegurando, por parte da administração, a estabilização das relações jurídicas emergentes de seus atos ou procedimentos, e na segunda, as obrigações de fazer atribuídas à administração, a fim de preservarem as expectativas legítimas depositadas pelos destinatários na função administrativa. ${ }^{16} \mathrm{E}$, nesse contexto, "extraem-se dessa confiança legitimamente depositada como consequências possíveis a preservação do próprio ato inválido ou a preservação de parte ou da totalidade de seus efeitos" ${ }^{17}$

A proteção à confiança decorre quando o comportamento da administração induziu a aparência de legalidade do ato. Passando a ter direito a verdadeiras consequências a serem produzidas após o ato. Não ocorre, assim, a proteção a esse princípio por qualquer tipo de convicção psicológica subjetiva do particular. Então, no caso terá direito a verdadeiras consequências a serem produzidas posteriormente pelo ato. ${ }^{18}$

Frisa-se que os atos do poder público têm aparência e presunção de legitimidade. Tais fatores vêm justificando sua conservação no mundo jurídico, independente se aqueles atos apresentam graves vícios ou não. Tal ocorre com os atos praticados por "funcionário de fato". Esses atos são considerados

15 CANOTILHO, J. J. Gomes. Direito constitucional e teoria da constituição. Coimbra: Almedina, 2000, p. 256 apud Couto e Silva, O princípio da segurança jurídica (proteção à confiança) no Direito Público Brasileiro e o direito da administração pública de anular seus próprios atos administrativos, op. cit., p. 11.

16 Maffini, Princípio da proteção substancial da confiança no direito administrativo brasileiro, op. cit., p. 123.

17 Ibid., p. 187.

18 Mello, O princípio da expectativa legítima e a exposição de motivos das medidas provisórias, op. cit., p. 179. 
válidos, mesmo que quem os determinou não tiver competência para isso. Tudo porque, como já referido no parágrafo acima, têm aparência de legitimidade. Em função disso, conclui-se que o direito protege não essa aparência, mas sim a confiança que as pessoas depositam no ato.

O princípio da confiança, diante de tais premissas, traz em seu núcleo os elementos da certeza e da previsibilidade. Nenhum deles gera axiomas, mas traz consigo a noção de que a confiança é invocável quando as condições de fato, em relação com o direito, possibilitem afirmar que determinada situação ocorrerá de certa forma. ${ }^{19}$

Os princípios da proteção da confiança e da segurança jurídica no direito comparado e no direito brasileiro podem ser relacionados a diversos temas dominantes, entre eles: a manutenção no ordenamento jurídico de atos administrativos inválidos por ilegais ou inconstitucionais, por exemplo, licenças, autorizações, subvenções, atos pertinentes a servidores públicos, tais como vencimentos e proventos, ou de seus dependentes, como pensões etc.; a responsabilidade do ente estatal pelas promessas firmes feitas por seus agentes, notadamente em atos relacionados com o planejamento econômico; a responsabilidade pré-negocial do Estado; o dever do Estado de estabelecer regras transitórias em função de mudanças radicais introduzidas no regime jurídico, por exemplo, da ordem econômica, do exercício de profissões, dos servidores públicos. ${ }^{20}$

A legislação da União, ${ }^{21}$ designada pela Lei no 9.784 , de 29 de janeiro de 1999 (arts. 2o e 54) ${ }^{22}$, pela Lei no 9.868, de 10 de novembro de 1999 (art. 27), e pela Lei no 9.882, de 3 de novembro de 1999 (art. 11), refere-se à segurança jurídica, quer como princípio geral da administração pública, de matriz constitucional, a justificar a permanência no mundo jurídico de atos administrativos inválidos, quer como valor constitucional a ser ponderado, em determinadas circunstâncias, em cotejo com os princípios da supremacia da Constituição

19 Ibid., p. 176.

20 Couto e Silva, O princípio da segurança jurídica (proteção à confiança) no Direito Público Brasileiro e o direito da administração pública de anular seus próprios atos administrativos, op. cit., p. 16.

21 Dispõem, respectivamente, sobre o processo administrativo da União, a ação declaratória de constitucionalidade, ação direta de inconstitucionalidade e a arguição de descumprimento de preceito fundamental.

22 A segurança jurídica, no plano infraconstitucional e no direito administrativo, tomou forma em alguns dispositivos da Lei no 9.784, de 29 de janeiro de 1999, que "regula o processo administrativo no âmbito da Administração Pública Federal". Passando a constar de forma expressa no art. 54 da lei, nos seguintes termos: "O direito da Administração de anular os atos administrativos de que decorram efeitos favoráveis para os destinatários decai em 5 (cinco) anos, contados da data em que foram praticados, salvo comprovada má-fé". 
e da nulidade ex tunc da lei inconstitucional. A norma do art. 54 da referida lei conjuga os aspectos de tempo e boa-fé, dirigindo-se essencialmente a estabilizar relações jurídicas pela convalidação de atos administrativos quinados de vício de legalidade.

Em decisões recentes do $\mathrm{STF}^{23}$ a segurança jurídica é qualificada como princípio constitucional na posição de subprincípio do estado de direito, harmonizando-se, assim, por esses arestos pioneiros da nossa mais alta Corte de justiça, linhas de entendimento já afloradas na doutrina, na legislação e em acórdãos de alguns tribunais, mas que passam a gozar, agora, de um valor e de uma autoridade que ainda não possuíam. $\mathrm{O}$ direito brasileiro trata muito pouco do princípio da confiança e, devido a isso, parece inequívoco que o referido princípio estatui o poder-dever de o administrador público zelar pela estabilidade decorrente de uma relação timbrada por uma autêntica fidúcia mútua, no plano institucional. ${ }^{24}$

Nos casos da legislação tributária, quando os princípios da segurança e da confiança são seguidos fielmente, faz cessar, por parte do Estado, a improvisão, a irresponsabilidade e o imediatismo com que muitas vezes os governos autoritários impõem a tributação, desorganizando a economia e desorientando a sociedade. Em suma, o respeito aos aludidos princípios, por parte dos governantes, acarreta efeitos de extrema importância em matéria de tributação, os quais incluem a segurança, a confiança e a certeza aos governados quanto à tributação; o respeito ao governo dos governados; e a responsabilidade pelos rumos da política tributária. ${ }^{25}$

${ }^{23}$ MC $-n^{\circ}$ 2.900-RS, $2^{\underline{a}}$ Turma, relator min. Gilmar Mendes (8-3-2003), Informativo do STF no 231 :

“(...) Em verdade, a segurança jurídica, como subprincípio do Estado de Direito, assume valor ímpar no sistema jurídico, cabendo-lhe papel diferenciado na realização da própria ideia de justiça material. (...)” MS 24268/MG, relator min. Gilmar Mendes (15-3-2004), Informativo do STF $n^{\circ} 343$ “(...)7. Aplicação do princípio da segurança jurídica, enquanto subprincípio do Estado de Direito. Possibilidade de revogação de atos administrativos que não se pode estender indefinidamente. Poder anulatório sujeito a prazo razoável. Necessidade de estabilidade das situações criadas administrativamente. (...)" e MS 22357/DF, relator min. Gilmar Mendes, DJU de 24-5-2004: “(...) 5. Obrigatoriedade da observância do princípio da segurança jurídica enquanto subprincípio do Estado de Direito. Necessidade de estabilidade das situações criadas administrativamente. 6. Princípio da confiança como elemento do princípio da segurança jurídica. Presença de um componente de ética jurídica e sua aplicação nas relações jurídicas de direito público. 7. Concurso de circunstâncias específicas e excepcionais que revelam: a boa-fé dos impetrantes; a realização de processo seletivo rigoroso; a observância do regulamento da Infraero, vigente à época da realização do processo seletivo; a existência de controvérsia, à época das contratações, quanto à exigência, nos termos do art. 37 da Constituição, de concurso público no âmbito das empresas públicas e sociedades de economia mista. (...)" (grifo nosso). FREITAS, Juarez. Estudos de direito administrativo. 2. ed. São Paulo: Frase, 1997. p. 59-60.

25 THEODORO JÚNIOR, Humberto. A onda reformista do direito positivo e suas implicações com o princípio da segurança jurídica. Revista Forense, Rio de Janeiro, v. 102, n. 387, p. 133-157, set./out. 2006. p. 142. 
Branco ${ }^{26}$ supera as definições básicas e vai além, referindo que a confiança é vista, no mínimo, por três pontos diferentes:

1) é fundante do ordenamento pela possibilidade de ser preservada ainda que não exista regra legal, constituindo-se em princípio para tomada de decisões judiciais, cujo papel é evitar que alguém se aproveite de uma posição que ocupa para obter vantagens, ainda que não sejam concedidas; 2) é um pressuposto para a existência de uma ordem jurídico-social, pois a preservação da confiança, por meio de promessas e do cumprimento de promessas, faz surgir regras que considerem o ponto de vista do outro, permitindo a convivência social; e, 3) tem a função de simplificação, limitando as possibilidades de comportamentos previsíveis, afastando perigos derivados da imprevisibilidade do comportamento humano.

Blanco, ${ }^{27}$ a respeito do tema, aponta duas situações nas quais a confiança está presente: a de que um dos fenômenos essenciais na delimitação do princípio é a tensão para conseguir um adequado equilíbrio entre a legalidade e a segurança como dois valores importantes e necessários no desenvolvimento do estado de direito. E a outra é a necessidade de purificação conceitual do instituto, determinando se a confiança deve ser protegida em razão das expectativas da pessoa na continuidade de sua posição.

O autor afirma que é manifestação da relevância da segurança jurídica a necessidade de se manter a confiança nas instituições. Assim, essa será sempre presente, mas nem sempre protegida, por não levar necessariamente à expectativa legítima. ${ }^{28}$

Quando a responsabilidade é gerada a partir da frustração da confiança ${ }^{29}$ depositada numa pessoa, pode ocorrer de ela se tornar devedora ou responsável perante quem nela confiou, mesmo sem ela ter pretendido obrigarse, nem cometido alguma falta, não tendo necessariamente agido com culpa

26 Branco, A proteção das expectativas legítimas derivadas das situações da confiança, op. cit., p. 177.

27 BLANCO, Federico A. Castillo. La protección de confianza en el derecho administrativo. Barcelona: Marcial Pons, 1998. p. 183-184.

28 Ibid., p. 106-110, passim.

29 Os dispositivos constantes dos arts. 100 e 146 do CTN são aplicações da proteção da confiança e da boa-fé objetiva. É fundamental que se preservem a estabilidade das relações jurídicas, a certeza e a segurança. $\mathrm{O}$ tribunais superiores vêm, igualmente, aplicando dessa forma o art. 146. Assim reza a Súmula 227 do antigo Tribunal Federal de recursos: "A mudança de critério jurídico adotado pelo fisco não autoriza a revisão de lançamento". 
ou dolo. Há, entretanto, uma condição básica que consiste no fato de ter o prejuízo decorrido da confiança que inspirou o responsável, criando-se uma expectativa em favor de outrem, que assim se torna credor no momento da frustração que passa a sofrer. ${ }^{30}$

Como já referido, os atos estatais podem criar expectativas para os indivíduos que, acreditando na validade e na estabilidade destes atos, seguem suas condutas no sentido indicado pelos mesmos, isto é, comportam-se conforme as expectativas legitimamente geradas; nesse sentido, tais condutas, pautadas pelo estado de confiança, precisam ser imunizadas aos atos contraditórios supervenientes do poder público (nulli conceditur venire contra factum proprium); o papel do princípio da proteção da confiança legítima é certamente conferir esta imunidade e, assim, deriva do princípio do estado de direito (Rechtsstaatsprinzip) e tem por conteúdo a realização da segurança jurídica. ${ }^{31}$

Pode-se dizer, então, que o princípio protege o direito adquirido e, também, a expectativa de adquirir direitos; se preocupa com fatos passados e com futuros, e, por fim, realiza a segurança jurídica como medida de justiça retrospectiva e prospectiva, de equidade, de justiça do caso concreto. ${ }^{32}$

Para Branco, ${ }^{33}$ o modelo jurídico da confiança é baseado em três elementos: valor, situação de fato e princípio jurídico. Desse modo, esse modelo tem a função de garantir segurança jurídica e preservar valores que sustentam a base das relações negociais. A confiança, como fato, é tutelada por muitas normas, porém existem algumas situações em que não há nenhum bem que o direito esteja tutelando, a não ser a própria confiança, caso em que o princípio da confiança ganha relevo, já que será da sua aplicação direta que resultarão os efeitos jurídicos. ${ }^{34}$

Constata-se que o venire contra factum proprium é a mais clara ofensa à confiança, pois esses casos se caracterizam justamente por ter uma posição jurídica diversa àquela que vinha sendo praticada pelo agente.

30 WALD, Arnaldo. O princípio da confiança. Revista Forense, Rio de Janeiro, v. 102, n. 386, p. 15-21, jul./ago. 2006. p. 21-22.

31 CAMPOS, Carlos Alexandre de Azevedo. Modificações da disciplina Infralegal do Paes e o princípio da proteção da confiança legítima. Revista Dialética de Direito Tributário, Porto Alegre, n. 135, p. 12-22, dez. 2006. p. 17.

32 Ibid., p. 18.

33 Branco, A proteção das expectativas legítimas derivadas das situações da confiança, op. cit., p. 180-181.

34 Ibid., p. 183. 
Nesse contexto, resta evidente que os princípios da segurança jurídica e da proteção à confiança são preceitos conservadores inseridos no mundo jurídico. São destinados à manutenção do status quo e a evitar a surpresa nas pessoas quando houver modificações do direito positivo ou na conduta estatal, até mesmo se manifestadas em atos ilegais, ferindo os interesses dos administrados ou frustrando as expectativas. ${ }^{35}$

Entende-se que a segurança jurídica e a proteção à confiança não são valores absolutos, pois não podem imobilizar o Estado a ponto de impedi-lo de alterar o que o interesse público o exigir. Por outro lado, o Estado não pode, em qualquer circunstância, mudar suas providências em contradição com as que foram por ele impostas, e surpreender os que nele depositaram confiança. Por isso, há elementos que limitam o que pode ou não ser alterado e, com isso, dever ser feito.

As disposições constitucionais se prestam a tal finalidade, marcando o âmbito e disciplinando os processos de revisão e emenda da própria Constituição ou impondo limites à liberdade de conformação do legislador ordinário. Ademais, resultam de construção jurisprudencial, como atesta o reconhecimento do princípio da proporcionalidade e, igualmente, do princípio da proteção à confiança no direito germânico e europeu, cuja observância é exigida de todos que exercem função estatal. ${ }^{36}$

Portanto, o princípio da confiança jurídica surge em nosso ordenamento para assegurar ao cidadão que esse não estará desamparado no mundo jurídico e será respeitado se confiar em expectativas e essa for frustrada. Gerando efeitos positivos e negativos, bem como limitando os poderes do Estado.

\section{A confiança jurídica e a alteração das normas indutivas}

Adentrando no foco principal do presente trabalho, começamos por definir quando a alteração das normas indutivas acarreta ao Estado o dever de indenizar. Definindo-as, são normas que "não forçam comportamentos, mas apenas incentivam, estimulam, ou impulsionam o desenvolvimento de

35 Couto e Silva, O princípio da segurança jurídica (proteção à confiança) no Direito Público Brasileiro e o direito da administração pública de anular seus próprios atos administrativos, op. cit., p. 12.

$36 \quad$ Ibid., p. 13. 
atividades pela iniciativa privada. Configuram normas dessa espécie aquelas que preveem incentivos creditícios e fiscais" ${ }^{37}$

Resta evidente que uma posterior mudança nas normas indutivas gera a responsabilidade estatal, cabendo oportunamente frisar que ocorrerá violação ao princípio da confiança jurídica. Complementando nosso argumento, Nobre Júnior reúne quatro condições para que seja imposta a responsabilidade civil do Estado nos casos de alteração das normas indutivas quando depositada a confiança, que são: “a) existência de norma indutiva, o qual não se teria realizado caso aquela não tivesse existido; b) não realização das condições previstas na norma; c) ocorrência de um dano; d) conexão entre o descumprimento da norma e o dano". ${ }^{38}$

Isso não significa dizer que o Estado, na condução da economia, não poderá alterar juridicamente as circunstâncias justificáveis pelo interesse público. O que se tem é que, como requisito às situações constituídas, ocorre a adesão do particular ao contido na norma jurídica de cunho indutivo.

Em nosso ordenamento, boa-fé objetiva é utilizada também como o princípio da proteção da confiança. Por isso, tratamos às vezes de boa-fé objetiva e, em outras, de proteção da confiança.

A ideia da proteção da confiança objetiva ou boa-fé objetiva é reconhecida como princípio de nossa ordem constitucional instituidora do estado democrático de direito, sendo, assim, implícito ao direito administrativo, ligada diretamente ao problema da prescritibilidade da pretensão anulatória dos atos da administração pública. ${ }^{39}$

A responsabilidade estatal pela alteração das normas indutivas, sem a salvaguarda das situações consolidadas, enfatiza:

O Estado, em algumas situações, incentiva mediante promessas concretas de vantagens e benefícios, clara e positivamente os indivíduos a um determinado comportamento, que a violação dessas promessas implica infringência ao princípio da boa-fé, cabendo ao Estado indenizar os danos decorrentes dessa confiança. São aqueles casos de caráter incitativo, em cuja implantação ou execução o Estado se compromete firmemente a propiciar benefícios de qualquer natureza, inclusive de

\footnotetext{
Nobre Júnior, O princípio da boa-fée e sua aplicação no direito administrativo brasileiro, op. cit., p. 292. Ibid., p. 293.

39 ANJOS, Luís Henrique Martins dos.; ANJOS, Walter Jone dos. Manual de direito administrativo. Porto Alegre: Livraria do Advogado, 2001. p. 69.
} 
índole fiscal. Certamente, o mesmo não ocorre nos planos meramente informativos, nos quais o Poder Público simplesmente coleta dados ou faz prognósticos e projeções. Nesses casos, cabe ao particular assumir os riscos pela aceitação ao plano. ${ }^{40}$

Pode-se concluir através disso que a responsabilidade defluiu da postura administrativa na fase de execução e não do plano em si. Sobre o tema, Figueiredo ${ }^{41}$ entende que há responsabilidade estatal pelos danos ocasionados pela modificação dos planos incitativos, onde está presente a concretização de várias medidas para que o Estado obtenha a colaboração da iniciativa privada, contam os administrados da iniciativa privada, que manifestam adesão, com a confiança, a boa-fé e a lealdade da administração. Algumas decisões ${ }^{42}$ são baseadas na lealdade e na boa-fé, preservando as situações constituídas antes que sofram alterações imprimidas pelo Estado.

E, para que a boa-fé objetiva norteie as relações-administrativas, tanto a administração como os administrados ficam limitados na atuação da conduta estatal, não podendo optar por determinada conduta que implique um resultado concreto inesperado pelos dados objetivos que o caso ofereça, mesmo que aquela conduta estivesse amparada inicialmente pela discricionariedade em se tratando da administração ou pela autonomia da vontade dos administrados. A boa-fé ou a proteção da confiança será ferida por esse resultado concreto.

Confiança aqui entendida como justamente aquela depositada no resultado que se poderia esperar dos dados objetivos da situação. Percebe-se que não há valoração da subjetividade do pensamento do administrador ou do administrado. Em razão disso, é princípio objetivo. ${ }^{43}$

Ressalta-se que nessas situações abordadas,

40 COUTO E SILVA, Almiro do. Responsabilidade do Estado e problemas jurídicos resultantes do planejamento. Revista de Direito Público, Porto Alegre, v. 14, n. 63, p. 28-36, jul./set. 1982. p. 33 .

41 FIGUEIREDO, Lúcia Valle. O devido processo legal e a responsabilidade do Estado por dano decorrente do planejamento. Revista Diálogo Jurídico, Salvador, n. 13, p. 1-21, abr./maio 2002. p. 14-15.

42 4- Turma do Tribunal Federal de Recursos. AMS 103.391 - SP. AC. U. relator: min. Antônio de Pádua Ribeiro, DJU de 21-2-85; SÃO PAULO. Tribunal Regional Federal. 3a Região. 4⿳亠丷a Turma. AMS 175.557 - SP. Ac. Un. relatora: juíza Lúcia Valle Figueiredo, DJU de 4-3-97.

43 Anjos e Anjos, Manual de direito administrativo, op. cit., p. 68. 
(...) indispensável ficar patenteada, além da adesão do particular à regra incitativa, a circunstância de o prejuízo ter a sua origem calcada em ato estatal que, uma vez alterada a sistemática normativa então vigente, postergue situações ao abrigo da segurança jurídica. Significa dizer que o dano advém de ato comissivo, a dar lugar à operatividade da teoria do risco administrativo. ${ }^{44}$

O Estado, então, atuando como ente econômico estatal e incentivando o indivíduo a cumprir determinada norma, ao descumpri-la, fica responsabilizado a indenizar os danos decorrentes da confiança.

\section{A confiança jurídica e o não cumprimento de promessas estatais}

Além da alteração das normas indutivas, quando o indivíduo deposita confiança, o Estado poderá atuar de modo declarativo, realizando promessas sobremaneira capazes de induzir os particulares a seguirem determinadas atividades, simplesmente pelo motivo de ser provido de seriedade, de clareza, de exequibilidade e de emanação pela autoridade competente à sua concretização. De mesmo modo, o seu descumprimento também poderá acarretar responsabilidade ao poder público. ${ }^{45}$

Canotilho tratou do assunto quando relata que são providos de interesse "certos actos da administração traduzidos em simples promessas, garantias ou engagements verbais com o propósito de incitar algumas empresas à realização de certas operações (promessa de um certo contingente de exportação, promessa de compra para o Estado de parte do fabrico etc.)" ${ }^{46}$ os quais podem gerar "um grau de confiança e boa-fé nos destinatários que os leve, ancorados na proteção administrativa, a arriscarem-se a negócios financeiramente ruinosos". ${ }^{47}$ Portanto, evidente a afirmação de que o Estado se vincula ao que prometera.

Sobressaindo-se sobre o tema, Decocq reconhece que a jurisprudência admite o dever de a administração cumprir as promessas feitas, mesmo

44 Nobre Júnior, O princípio da boa-fé e sua aplicação no direito administrativo brasileiro, op. cit., p. 298.

45 Ibid., p. 299.

46 Canotilho, Direito constitucional e teoria da constituição, op. cit., p. 299.

47 Ibid., p. 299. 
quando contrárias à lei, sejam explícitas ou implícitas. Confere, para tanto, a presença de cinco condições: a primeira é a precisão da promessa com relação ao seu objeto e destinatários; a segunda é a competência, real ou aparente, da autoridade que a realizou; a terceira é sua legalidade aparente; a quarta é a existência de um prejuízo importante, a resultar do comportamento adotado pelo cidadão ao pôr fé ao prometido; e a quinta é a ausência de alteração legislativa entre o momento da promessa e aquele em que o princípio da boafé é invocado. ${ }^{48}$

Nobre Júnior, acrescentando o entendimento do autor retromencionado, faz algumas ponderações sobre o assunto. Relata que é necessário também que o prometido porte exequibilidade, sendo suscetível de concretização. Além do mais, a tutela à segurança jurídica no direito brasileiro possui estatura constitucional - artigo 5º, inciso XXXVI, da Constituição Federal de 1988 (e não legal - art. 2º do Código Civil de 1804), assim, inaplicável a (quinta) condição que o autor mencionou, ou seja, entre o prometido e a suscitação de ofensa à boa-fé, não tendo ocorrido alteração nos diplomas legais regentes da matéria não cabe ao caso. ${ }^{49}$

Observa-se que o dano poderá ser produzido por ato administrativo baseado ou não em norma legal, determinando o não cumprimento da promessa, ou da mera inércia do poder público em cumprir com a referida promessa. Ademais, invoca-se tanto a teoria do risco administrativo como a da culpa administrativa, tributada ao funcionamento imperfeito da atividade administrativa.

A violação da boa-fé, para muitos doutrinadores, entre eles Almiro do Couto e Silva, ${ }^{50}$ resolve-se mediante reparação pecuniária, limitada ao dano emergente, porém, Nobre Júnior ${ }^{51}$ não aceita tal ensinamento. Aufere à expressão responsabilidade estatal um conceito amplo, não podendo limitar-se ao pagamento de indenização. O Estado tem o compromisso de ajustar-se ao cumprimento da ordem jurídica, implicando, nas situações enfocadas, se assegurar o direito de determinado administrado ver mantidas as

48 La bonne foi dans les relations entre l'État et les particuliers, Rapport General. In: ASSOCIATION HENRI CAPITANT. La bonne foi (Journées lousianaises). Paris: Litec, 1992. t. XLIII, p. 371. Averba André Laubadére (Direito Público Econômico. Tradução: Maria Teresa Costa. Coimbra: Almedina, 1985. p. 446) apud Nobre Júnior, O princípio da boa-fé e sua aplicação no direito administrativo brasileiro, op. cit., p. 300.

49 Nobre Júnior, O princípio da boa-fé e sua aplicação no direito administrativo brasileiro, op. cit., p. 300.

50 Couto e Silva, Responsabilidade do Estado e problemas jurídicos resultantes do planejamento, op. cit., p. 34 .

51 Nobre Júnior, O princípio da boa-fé e sua aplicação no direito administrativo brasileiro, op. cit., p. 302-303. 
condições da norma indutiva, ou de obter a satisfação das promessas feitas pela administração. Esgotadas as chances de tais prestações serem obtidas, podemos tratar das substituições ao pagamento em pecúnia. Ao propender pela manutenção da sistemática perfilhada pela norma indutiva revogada, com relação às pessoas que já se encontravam sob o seu pálio protetor, bem como a execução das promessas como divulgadas pelo órgão estatal. ${ }^{52}$

Além do mais, quando ocorrer prejuízo entre o ultraje ao direito e o restabelecimento do estado jurídico a que o agente faz juz, devem esses danos ser reparados de forma autônoma. Por exemplo, ${ }^{53}$ a supressão de incentivo fiscal, realizada indevidamente, com relação a certo indivíduo, este poderá ser forçado a suportar maiores encargos tributário, porquanto não recomposta a ordem jurídica pela intervenção judicial. O ressarcimento ao administrado era completo diante do pagamento aos encargos tributários.

Como já tratado anteriormente e convém aqui argumentar, a frustração de expectativas é algo ineliminável na atividade estatal. O Estado, em determinados comportamentos, incentiva de forma tão clara e positiva os indivíduos a certa situação, mediante promessas concretas de vantagens e benefícios, que a violação dessas promessas acarreta infringência ao princípio da boa-fé, devendo o Estado indenizar os danos decorrentes dessa confiança depositada. Nos planos meramente informativos, nos quais o Poder Público simplesmente coleta dados ou faz prognósticos e projeções, isso não ocorre, cabendo ao particular assumir os riscos pela adoção de alguns dos caminhos não previstos pelo plano, mas sim naqueles de caráter incitativo, em cuja implantação ou execução o Estado se compromete firmemente a propiciar benefícios de qualquer natureza, inclusive de índole fiscal. Oportuno lembrar que a responsabilidade do Estado, na maioria das vezes, está ligada ao procedimento da administração pública na fase da execução do plano, e aos atos concretos que pratica visando a esse fim e, poucas vezes, poderá derivar do plano em si. ${ }^{54}$

Portanto, para imputar ao Estado a responsabilidade, devemos nos certificar de que as expectativas foram realmente geradas e se essas deram causa a direito subjetivo. Para isso, necessário se faz saber se as promessas foram realmente firmes, precisas e concretas. Caso positivo, a alteração posterior

52 SCAFF, Fernando Facury. Responsabilidade do Estado intervencionista. São Paulo: Saraiva, 1990. p. 118.

53 Nobre Júnior, O princípio da boa-fé e sua aplicação no direito administrativo brasileiro, op. cit., p. 302-303.

54 Couto e Silva, Responsabilidade do Estado e problemas jurídicos resultantes do planejamento, op. cit., p. 33. 
do plano, ainda que efetuada mediante lei, decorre no dever de indenizar os danos decorrentes da confiança, abrangendo apenas a reparação do interesse negativo e não dos lucros que o particular teria, caso fossem mantidas as mesmas condições.

Ademais, a expectativa legítima está intimamente ligada à explicação da proteção ressarcitória quando depositada confiança nos casos de descumprimento das promessas estatais, pois se criam aí condições de fato pela administração pública, induzindo o indivíduo a determinado comportamento administrativo subsequente, correspondente aos fatos que a geraram (necessariamente ligados aos elementos acidentais - definidos conforme vimos anteriormente). Haverá, portanto, restrição mútua da liberdade, gerando eficácia negativa do princípio da confiança, impondo à administração deveres de não fazer. ${ }^{55}$

Por conseguinte, quando a expectativa gerada ocorre diretamente entre a administração e o indivíduo, chamamos de atos administrativos stricto sensu, e, quando ocorre entre esses sujeitos, mas de forma indireta, chamamos de atos administrativos lato sensu (políticos). Por exemplo, a sociedade, ouvindo as razões e promessas da administração em determinada exposição de motivos, terá a expectativa por meio de seu representante parlamentar, o qual confia que seu eleitor quereria a edição da lei, assim criando expectativa por ele, e votando a favor da conversão em lei - conforme suas propostas de campanha que conquistaram o voto de determinado segmento da sociedade. Assim, tem-se o direito de exigir as consequências jurídicas que a administração promoveu na exposição de motivos. ${ }^{56}$

Diante disso, se o Estado pretende tributar ou aumentar tributos, deve deixar explícita qual a finalidade de tal ato, bem como justificá-la. A justificação é vinculante para o administrador e ocorre pela fundamentação; por exemplo, o caso da recente majoração de alíquotas do ICMS no Rio Grande do Sul. Quando o governador do estado expressamente utilizou como causa a insuficiência de recursos do estado, conquistou a maioria parlamentar necessária e até mesmo a tolerância da opinião pública. ${ }^{57}$

Por derradeiro, quando os efeitos surtidos forem contrários aos prometidos na exposição de motivos, o Estado deve ser responsabilizado, não

55 Martins-Costa, A proteção da legítima confiança nas relações obrigacionais entre a administração e os particulares, op. cit., p. 228-255, passim.

56 Mello, O princípio da expectativa legítima e a exposição de motivos das medidas provisórias, op. cit., p. 191-192.

57 Ibid., p. 192. 
deixando o contribuinte desamparado. Outro exemplo dado por Mello ${ }^{58}$ demonstra o caso: o Estado afirma, promete ao contribuinte que determinado programa propiciará economia tributária, e depois de aderir, prestando-lhe confiança, ele passa a pagar mais tributos. O contribuinte poderá desvincularse do programa, independentemente do tempo acordado.

A exposição de motivos das medidas provisórias, vinculando o administrador e obedecendo aos princípios constitucionais da administração pública, origina na sociedade legítima expectativa por intermédio do Parlamento. Caso não ocorram os efeitos pretendidos, a sociedade terá direito a exigir indenização ou, em se tratando de medida provisória tributária, exigir a volta ao regime anterior ou sua inclusão em regime especial adequado à situação do contribuinte. ${ }^{59}$

Portanto, para ser invocada a expectativa legítima pelo indivíduo, é necessário um comportamento concreto da administração que o justifique, ainda que não haja legislação aplicável de plano, e o potencial vinculativo de tal comportamento é indefinível prima facie, variando conforme os elementos acidentais adicionados à confiança. ${ }^{60}$

Em suma, há posições divergentes sobre a natureza do dano ressarcível pelo Estado ao indivíduo nos casos analisados. Alguns entendem que devemos esgotar as alternativas de assegurar o direito, mantendo as condições das normas indutivas e/ou obtendo a satisfação das promessas feitas pela administração e, após isso, poderão pretender a substituição do prejuízo pelo pagamento em pecúnia. E outros entendem que a indenização pecuniária se faz logo quando verificado o prejuízo. Sempre verificando se as promessas foram realmente firmes, precisas e concretas.

\section{Conclusão}

O trabalho apresentado, atendo-se aos livros, artigos e jurisprudências, propôs-se a defrontar o tema da proteção ressarcitória do Estado nos casos de

58 Ibid., p. 193.

59 4a Turma. RMS 6.183/MG. Relator: ministro Ruy Rosado de Aguiar. Julgado em: 14-11-1995, publicado no DJ em 18-12-1995, p. 44.573; 6 Turma. Resp nº 162424-ES. Relator: ministro Vicente Leal, DJ 11-5-1998, p. 00173. RE (Agr) 217.141/SP; STF. Mandado de Seg. no 22164, relator: ministro Celso de Mello, DJ 17-11-95, p. 39206; MS no 4.772/DF contra ministro da Fazenda. Relator: min. Adhemar Maciel, decisão da 1ª Seção de 12-11-1997. Acompanharam o relator os ministros José Delgado, Humberto Gomes de Barros, Hélio Mosimann e Milton Luiz Pereira.

60 Mello, O princípio da expectativa legítima e a exposição de motivos das medidas provisórias, op. cit., p. 198. 
alteração de normas indutivas e de descumprimento de promessas estatais. $\mathrm{O}$ Estado, como pessoa jurídica pública, é suscetível de responsabilidade civil ou patrimonial sempre que seus prepostos, por ação ou omissão, causarem danos a particulares.

Contudo, deve ser analisado também o comportamento do prejudicado na ocasião em que ocorreu o dano, configurando ou não a responsabilidade do Estado, dependendo, assim, se houve contribuição no prejuízo por parte do lesado. Devido à complexidade do tema, ao dano não pode ser atribuído um conceito único. O dano ou prejuízo - moral ou material - é o resultado da lesão, qual é a perda patrimonial sofrida pelo sujeito.

Em consequência do dano, recai a indenização devida pelo Estado que é o resultado do dano material ou patrimonial, devendo o Estado arcar com todo o prejuízo sofrido pelo ofendido, não podendo ser nem inferior nem superior aos prejuízos refletidos no patrimônio da vítima. Pois, no direito ressarcitório, não há tarifação legal para limitar o montante de indenização. Para tanto, deve haver uma relação de causalidade necessária e suficiente entre a ação ou omissão do Estado e o efeito danoso.

Depois de auferidos estes aspectos, verifica-se que a administração pública, pronunciando-se no mundo jurídico, pode ensejar legítimas expectativas no particular, devendo essa expectativa ser tutelada. A expectativa legítima gera confiança nos indivíduos, bem como surge de uma situação de fato.

Os requisitos da tutela da confiança, formulados por meio das normas constitucionais aplicáveis ao caso, bem como jurisprudência do STF, são a relação entre um dos poderes estatais com um ou mais particulares; os atos ou comportamentos estatais a despertar a confiança; a aparência de legitimidade do ato; o nexo de causalidade entre o poder público e a confiança estimulada; e a ocorrência de prejuízo ao particular.

Atualmente, está muito em voga o tema da confiança, ainda não delineados perfeitamente os conceitos jurídicos a esta, pois no Brasil é pouco tratada. Porém, alguns que abordam o assunto se referem à confiança, à segurança jurídica e à boa-fé como todos sinônimos. Assim, entende-se que são princípios muito próximos, que designam da mesma compreensão que também é estrutura no âmbito daquele conteúdo ético que deve estar presente nas relações jurídicas, vindo a ser imprescindível para o direito alcançar o seu fim de pacificador das condutas sociais.

Nesse sentido, a confiança pode ensejar a responsabilidade, uma vez que o indivíduo tenha efetivamente acreditado na situação aparentemente verdadeira. Em decorrência disso, podemos afirmar que o Estado poderá 
sofrer limitações em sua atuação. São exemplos concretos as normas indutivas e o descumprimento de promessas estatais. A primeira estimula o indivíduo a agir conforme a norma e o induz a acreditar que a norma será vantajosa para si, e, ao fim, a norma não é realizada como previsto, gerando um dano. Deve haver conexão entre o quantum alterado da norma e o dano.

$\mathrm{Na}$ segunda, o Estado declara promessas, induzindo o particular a segui-las. Tendo em vista que se trata de autoridade competente para sua concretização, e a norma tem aparência de legalidade. Do resultado decorre o prejuízo, e esse deve ser ressarcível.

\section{Referências}

ANJOS, Luís Henrique Martins dos; ANJOS, Walter Jone dos. Manual de direito administrativo. Porto Alegre: Livraria do Advogado, 2001.

BLANCO, Federico A. Castillo. La protección de confianza em el derecho administrativo. Barcelona: Marcial Pons, 1998.

BRANCO, Gerson Luiz Carlos. A proteção das expectativas legítimas derivadas da situações da confiança: elementos formadores do princípio da confiança e seus efeitos. Revista de Direito Privado, n. 12, v. 3, p. 169-225, out./ dez. 2002.

CAHALI, Yussef Said. Responsabilidade civil do Estado. 2. ed. ampl. rev. e atual. São Paulo: Malheiros, 1995.

CAMPOS, Carlos Alexandre de Azevedo. Modificações da disciplina Infralegal do Paes e o princípio da proteção da confiança legítima. Revista Dialética de Direito Tributário, Porto Alegre, n. 135, p. 12-22, dez. 2006.

CARVALHO FILHO, José dos Santos. Manual de direito administrativo. 14. ed. rev. ampl. atual. Rio de Janeiro: Lumen Juris, 2005.

COUTO e SILVA, Almiro do. Responsabilidade do Estado e problemas jurídicos resultantes do planejamento. Revista de Direito Público, Porto Alegre, v. 14 , n. 63 , p. 28-36, jul./set. 1982.

- A responsabilidade extracontratual do estado no direito brasileiro. Revista de Direito Administrativo, Rio de Janeiro, v. 202, p. 19-41, out./dez. 1995. 
- O princípio da segurança jurídica (proteção à confiança) no direito público brasileiro e o direito da administração pública de anular seus próprios atos administrativos: o prazo decadencial do art. 54 da Lei do processo administrativo da União (Lei n. 9.784/99). Revista Brasileira de Direito Público - RBDP, Belo Horizonte, v. 2, n. 6, p. 7-59, jul./set. 2004.

CRETELLA JÚNIOR, José. Direito administrativo brasileiro. 2. ed. Rio de Janeiro: Forense, 2000.

. Manual de direito administrativo: curso moderno de graduação. 7. ed. Rio de Janeiro: Forense, 2005.

DERGINT, Augusto do Amaral. Responsabilidade do Estado por atos judiciais. São Paulo: RT, 1994.

DI PIETRO, Maria Sylvia Zanella. Direito administrativo. 17. ed. São Paulo: Atlas, 2004.

FIGUEIRA JÚNIOR, Joel Dias. Responsabilidade civil do Estado-juiz. Curitiba: Juruá, 1995.

FREITAS, Juarez. Estudos de direito administrativo. 2. ed. São Paulo: Frase, 1997. GASPARINI, Diógenes. Direito administrativo. 7. ed. rev. e atual. São Paulo: Saraiva, 2002.

JUSTEN FILHO, Marçal. A responsabilidade do Estado. In: FREITAS, Juarez (Org.). Responsabilidade civil do Estado. São Paulo: Malheiros, 2006. p. 170-197.

MAFFINI, Rafael Da Cás. Princípio da proteção substancial da confiança no direito administrativo brasileiro. Porto Alegre: Verbo Jurídico, 2006.

MARTINS-COSTA, Judith. A proteção da legítima confiança nas relações obrigacionais entre a administração e os particulares. Revista da Faculdade de Direito da Universidade Federal do Rio Grande do Sul, Porto Alegre, n. 22, p. 228-257, set. 2002.

- A ressignificação do princípio da segurança jurídica na relação entre o Estado e os cidadãos: a segurança como crédito de confiança. Revista CEJ, Brasília, v. 8, n. 27, p. 110-120, out./dez. 2004.

MEDAUAR, Odete. Direito administrativo moderno. 9. ed. rev. atual. São Paulo: Revista dos Tribunais, 2005. 
MELLO, Eduardo Brigidi de. O princípio da expectativa legítima e a exposição de motivos das medidas provisórias. Revista Tributária e de Finanças Públicas, São Paulo, v. 14, n. 66, p. 173-198, jan./fev. 2006.

MELLO, Oswaldo Aranha Bandeira de. Princípios de direito administrativo. Rio de Janeiro: Forense, 1960. v. II.

MELLO, Celso Antônio Bandeira de. Curso de direito administrativo. 20. ed. rev. e atual. até a Emenda Constitucional 48, de 10.8.2005. São Paulo: Malheiros, 2006.

MORAES, Alexandre de. Direito administrativo. 19. ed. São Paulo: Atlas, 2006. . Direito constitucional administrativo. 2. ed. São Paulo: Atlas, 2005.

NASCIMENTO, Tupinambá Miguel Castro do. Responsabilidade civil do Estado. Rio de Janeiro: Aide, 1995.

NOBRE JÚNIOR, Edílson Pereira. O princípio da boa-fé e sua aplicação no direito administrativo brasileiro. Porto Alegre: Sérgio Antônio Fabris, 2002.

PORTO, Éderson Garin. O princípio da proteção da confiança e a boa-fé objetiva no direito público. Revista da Ajuris, Porto Alegre, v. 33, n. 102, p. 127-142, 2006.

SCAFF, Fernando Facury. Responsabilidade do Estado intervencionista. São Paulo: Saraiva, 1990.

SHONBERG, Soren J. Legitimate expectations in administrative law. Oxford: Oxford, 2000.

SILVA, Juary C. A responsabilidade do Estado por atos judiciários e legislativos. São Paulo: Saraiva, 1985.

THEODORO JÚNIOR, Humberto. A onda reformista do direito positivo e suas implicações com o princípio da segurança jurídica. Revista Forense, Rio de Janeiro, v. 102, n. 387, p. 133-157, set./out. 2006.

TRUJILLO, Elcio. Responsabilidade do Estado por ato lícito. São Paulo: Editora de Direito, 1996. 